\title{
In memory of James Tait Goodrich
}

\author{
Rick Abbott ${ }^{1}$ \\ Published online: 15 August 2020 \\ (C) Springer-Verlag GmbH Germany, part of Springer Nature 2020
}

James T. Goodrich MD, PhD, is leaving a legacy. It is certainly felt here at his home institution, Montefiore Health System and Albert Einstein College of Medicine. From his office, a cross between a museum of antiquity and a hall of marvels, to an internationally renowned craniofacial program, to his approach to care that was cherish by his patients, and to his impact on our trainees and his colleagues, he has left a strong mark. He has also left a legacy for pediatric neurosurgery. Throughout his career, he continuously stressed that knowing the historical struggles exerted to best an affliction lead to important insights on how it could be conquered.

Jim was loved by his patients and their families. They felt his confidence that he could help but also his core belief that his job was to treat the problem to enable their child to grow and prosper. He celebrated in accomplishing this, attending birthday parties, graduations, and the other important waypoints in his young patients as they grew. His patients' families knew that he had joined their fight to have their child mature into normal adulthood. I would occasionally bump into the strength of this bond when covering a health crisis in one of his patients. The moment I suggested a treatment approach, the family knew differed from Jim's. I would see a sense of confusion and mistrust arise in their eyes. I knew I was going to have a hard time regaining their trust that I was capable of caring for their child's emergency.

Our residents loved Jim and have been devastated by his passing. Their relationship started during their candidate interviews when he would first ask, while staring into your eyes, "So, just what can you bring to our program." He would also invariably work into the interview the question "Do you know the difference between an agent 007 and a 0013." They would look puzzled. He would then say with a twinkle in his eye "A 007 has a license to kill, a 0013 kills. I am trying to see which you are." A unique way to project how seriously he was committed to their training, but I imagine it made the desired impression. As they entered their training, our residents' initial impression of his commitment was quickly confirmed. For years the library in his cramped office was used by our residents for their call room, leaving the typical appearance of pizza boxes, used scrubs and crumpled lab coats. My sense is he welcomed this chaos as it afforded him intimate contact with them. And he used this closeness to impart in them the need for total commitment to a patient when delivering care, regardless of the personal sacrifice this commitment entailed.

Jim was sought out by his colleagues for advanced education in craniofacial reconstruction. After his death, I have received numerous condolences from surgeons around the world bemoaning his loss. I was struck by the depths of their grief and the indebtedness they felt for the selfless assistance he had given many in managing their difficult cases. His knowledge of not only the modern techniques but of the historical methods and mistakes in managing the neurosurgical ailments in children was valued profoundly.

Jim was a remarkable presence, and his knowledge, educational skills, and commitment to children will be missed but remembered. We are fortunate to have had him as one of us.

Publisher's note Springer Nature remains neutral with regard to jurisdictional claims in published maps and institutional affiliations.
Rick Abbott

rickabbott@me.com

1 Department of Neurosurgery and Pediatrics, Albert Einstein College of Medicine, Montefiore Medical Center, 111 E. 210th St, Bronx, NY 10467, USA 